\title{
PENGARUH MODEL PEMBELAJARAN LEARNING CYCLE 5E DISERTAI MIND MAP TERHADAP HASIL BELAJAR IPA BIOLOGI SISWA KELAS VIII SMP NEGERI 5 KARANGANYAR TAHUN PELAJARAN 2015/2016
}

\section{THE INFLUENCE OF LEARNING CYCLE 5E LEARNING MODELS ACCOMPANIED MIND MAP TOWARD BIOLOGY LEARNING ACHIEVMENT OF VIII GRADE STUDENTS AT SMP NEGERI 5 KARANGANYAR ACADEMIC YEAR 2015/2016}

\section{HARGIONO, MARIDI, BOWO SUGIHARTO}

Program Studi Pendidikan Biologi

Fakultas Keguruan dan Ilmu Pendidikan

Universitas Sebelas Maret

Jl. Ir. Sutami 36 A, Surakarta, 57126, Indonesia

*Corresponding Author: argicha45@gmail.com

Manuscript received : 14 Juni 2016 Revision accepted: 15 Agustus 2016

\begin{abstract}
The purpose of this research is to ascertain the influence of learning cycle 5E models accompanied mind map toward biology learning achievment of VIII grade students at SMP Negeri 5 Karanganyar academic year 2015/2016. This research was quasi experiment research which used posttest only nonequivalent control group design. This research applied learning cycle 5E learning models accompanied mind map in experimental group and direct instruction learning models in control group. The population of this research was all of VIII grade students at SMP Negeri 5 Karanganyar in academic year 2015/2016. Sampling techniques used cluster sampling that choosed VIII A, VIII B, and VIII G as experiment group, and VIII H as control group. Data was collected using multiple choice test, observation sheet, and document. The hypotheses analyzed by anova test. Result of data analysis using one way anova showed that experiment group with application of learning cycle 5E learning models accompanied

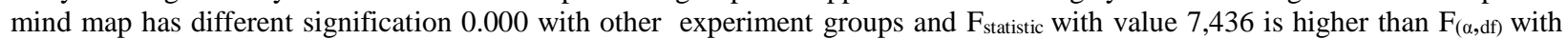
value 2,440.This research concluded that application of learning cycle 5E learning models accompanied mind map has real influential toward student's biology learning achievement of VIII grade students at SMP Negeri 5 Karanganyar especially cognitive domain.
\end{abstract}

Keywords : learning cycle 5E, mind map,learning achievment.

\section{PENDAHULUAN}

Pembelajaran IPA biologi pada tingkat Sekolah Menengah Pertama (SMP) memiliki tiga misi utama yaitu aspek empiris, evaluasi, dan sintas. Aspek empiris (purpose in empirical evidence) merupakan upaya mengenali proses kehidupan nyata di lingkungan, aspek evaluasi (purpose in human institution) merupakan upaya mengenali diri sendiri sebagai makhluk, sedangkan aspek sintas (purpose in human life) merupakan harapan bahwa biologi dapat bermanfaat untuk peningkatan kualitas kehidupan manusia dan lingkungannya (Rustaman, et al., 2008).

Biologi sebagai salah satu rumpun mata pelajaran IPA berkaitan erat dengan cara mencari tahu (inkuiri) tentang alam dan kehidupan yang ada di dalamnya secara sistematis. Pelaksanaan pembelajaran biologi tidak hanya bertujuan untuk mengumpulkan pengetahuan yang berupa fakta, konsep, dan prinsip semata, namun juga menekankan proses penemuan ilmu biologi. Mayoritas siswa SMP menganggap bahwa materi ajar biologi merupakan materi hafalan sehingga metode belajar yang sering digunakan adalah metode hafalan. Metode hafalan bersifat memori jangka pendek (short therm memory) dan berpengaruh terhadap hasil belajar siswa yang kurang. Hasil belajar merupakan perubahan tingkah laku akibat dari proses pembelajaran (Purwanto, 2013).

Salah satu model pembelajaran yang dapat mengkonstruksi pengetahuan siswa adalah Learning Cycle (Dahar, 2011). Learning cycle mengalami perkembangan menjadi 5 fase (learning cycle 5E). Learning cycle 5E menurut Shoimin (2014) memiliki kelebihan yaitu meningkatkan motivasi belajar karena siswa dilibatkan secara aktif di pembelajaran sehingga pembelajaran menjadi lebih bermakna. Model pembelajaran learning cycle 5E terdiri dari lima tahapan yang diawali dengan tahap engagment (pembangkitan minat), bertujuan untuk mendapatkan 
perhatian siswa, mendorong kemampuan berfikir membantu mereka mengakses pengetahuan awal yang telah dimiliki (Bybee, et al., 2006).

Tahap kedua dari learning cycle 5E adalah exploration (eksplorasi), siswa bekerja sama dalam kelompok untuk menguji hipotesis atau membuat hipotesis baru beserta alternatif pemecahannya. Peranan guru dalam tahap ini menurut Bybee (2009) adalah sebagai fasilitator.

Tahap ketiga model learning cycle 5E adalah explanation (penjelasan konsep). Siswa menjelaskan konsep baru yang mereka peroleh selama tahap exploration dengan pemahaman, bahasa, dan kalimat mereka sendiri. Wena (2009) menyebutkan bahwa pada tahap ini, guru dituntut mendorong siswa untuk menjelaskan konsep dengan kalimat/pemikiran sendiri, meminta bukti dan klarifikasi atas penjelasan siswa dan saling mendengar secara kritis penjelasan antar siswa atau guru.

Elaboration/extend (elaborasi) merupakan tahap keempat dari model learning cycle 5E. Siswa akan menerapkan konsep dan keterampilan yang telah dipelajari dalam situasi baru atau konteks yang berbeda. Bybee, et al. (2006) menyebutkan bahwa diskusi kelompok dan situasi cooperative learning memberikan kesempatan siswa untuk mengekspresikan pemamahan dan menerima umpan balik dari teman.

Tahap terakhir dari model learning cycle 5E adalah evaluation (evaluasi). Tahap evaluation mendorong siswa untuk menilai pemahaman dan kemampuan mereka serta memberikan kesempatan bagi guru untuk mengevaluasi kemajuan siswa.

Mind map merupakan salah satu teknik mencatat yang kreatif, efektif, dan memetakan pikiran-pikiran sehingga memudahkan untuk menempatkan informasi ke dalam otak dan memudahkan saat mengingat. Keunggulan mind map menurut Buzan (2013) adalah mengaktifkan kinerja otak, memungkinkan siswa lebih fokus pada pokok bahasan, dan membantu siswa dalam mengalihkan informasi dari ingatan jangka pendek ke ingatan jangka panjang.

Learning cycle 5E menekankan pendekatan proses dalam pembelelajaran, sedangkan mind map akan memudahkan siswa dalam mengingat serta melatih berpikir kreatif dan solutif sehingga perpaduan ini secara teoritis akan berimbas baik terhadap hasil belajar.

Belajar menurut Aunurahman (2012) adalah suatu proses di mana dalam proses tersebut terjadi interaksi baik antar individu maupun dengan lingkungannya sehingga membentuk suatu pengalaman tertentu yang mampu menghasilkan perubahan tingkah laku berupa kecakapan, sikap, kebiasaan, kepribadian atau pengertian. Sudjana (2011) menambahkan bahwa belajar merupakan kegiatan secara sadar dilakukan oleh pembelajar yang memungkinkan terjadinya perubahan pada dirinya, baik berupa tingkah laku maupun kemampuankemampuan tertentu.

Hasil belajar kognitif terbagi menjadi dua dimensi yaitu dimensi proses kognitif dan dimensi pengetahuan Dimensi proses kognitif terdiri atas enam kategori, yakni mengingat, memahami, mengaplikasikan, menganalisis, mengevaluasi, dan mencipta. Dimensi pengetahuan dibagi menjadi empat katgori, yakni faktual, konseptual, prosedual, dan metakognitif. (Anderson \& Krathwohl, 2010). Hasil belajar afektif dibagi menjadi penerimaan (A1), partisipasi (A2), penilaian (A3), organisasi (A4), dan internalisasi (A5). Hasil belajar psikomotorik terdiri dari perspsi (P1), kesiapan (P2), gerakan terbimbing (P3), gerakan terbiasa (P4), gerakan kompleks (P5), penyesuaian pola gerak (P6), dan kreativitas (P7) (Aunurrahman, 2012).

Penelitian ini bertujuan untuk mengetahui pengaruh penerapan model pembelajaran learning cycle 5E disertai mind map terhadap hasil belajar siswa kelas VIII SMP Negeri 5 Karanganyar tahun pelajaran 2015/2016.

\section{METODE PENELITIAN}

Penelitian in dilaksanakan di SMP Negeri 5 Karanganyar pada kelas VIII pada semester genap tahun pelajaran 2015/2016. Penelitian ini merupakan eksperimen semu dengan Post-test Only Nonequivalent Control Group Design.

Populasi dalam penelitian adalah seluruh siswa kelas VIII semester ganjil SMP Negeri 5 Karanganyar tahun pelajaran 2015/2016 sebanyak 8 kelas. Teknik pengambilan sampel yang digunakan pada penelitian adalah cluster sampling. Cluster sampling merupakan cara pengambilan sampel di mana unit sampelnya berupa kumpulan atau kelompok (cluster) unit observasi. Anggota populasi dibagi dalam beberapa kelompok, selanjutnya dilakukan pengambilan sampel pada kelompok terpilih (Somantri \& Muhidin, 2006)

Populasi yang terdiri dari 8 kelas dipilih 4 kelas terpilih sebagai sampel, kemudian tiap kelas sampel diberi perlakuan model pembelajaran yang berbeda. Perlakuan masing-masing kelas sampel tersaji dalam Tabel 1.

Tabel 1. Perlakuan pada Kelas Sampel.

\begin{tabular}{ll}
\hline Kelompok & Penererapan Model Pembelajaran \\
\hline Perlakuan 1 & Learning cycle 5E + mind map \\
Perlakuan 2 & Learning cycle 5E \\
Perlakuan 3 & Direct instruction + mind map \\
Kontrol & Direct instruction \\
\hline
\end{tabular}


Pengumpulan data dilakukan dengan metode tes untuk mengukur hasil belajar ranah kognitif. Uji hipotesis menggunakan uji anava satu jalan dengan uji lanjut uji LSD. Uji statistik dilakukan pada taraf signifikansi 0,05.

\section{HASIL DAN PEMBAHASAN}

Data hasil penelitian ini berupa hasil belajar siswa yang diperoleh dari tes evaluasi pembelajaran biologi pada materi fotosintesis dan respirasi tumbuhan. Tes dilakukan dengan mengunakan soal berupa pilihan ganda dan uraian. Data hasil belajar ranah kognitif siswa pada kelompok kontrol dan kelompok perlakuan terangkum dalam Tabel 1.

Tabel 2. Rangkuman Data Hasil Belajar Siswa Ranah Kognitif

\begin{tabular}{ccccc}
\hline Kelas & $\begin{array}{c}\text { Kelompo } \\
\mathbf{k} \\
\text { Kontrol }\end{array}$ & $\begin{array}{c}\text { Kelompo } \\
\mathbf{k} \\
\text { Perlakua } \\
\mathbf{n ~ 1}\end{array}$ & $\begin{array}{c}\text { Kelompo } \\
\mathbf{k} \\
\text { Perlakua } \\
\mathbf{n ~ 2}\end{array}$ & $\begin{array}{c}\text { Kelompo } \\
\mathbf{k} \\
\text { Perlakua } \\
\mathbf{n ~ 3}\end{array}$ \\
\hline Rata-rata & 59,233 & 72,290 & 62,867 & 60,941 \\
Standar & 12,982 & 10,077 & 13,001 & 11,452 \\
Deviasi & & 101,546 & 169,016 & 131,148 \\
Variansi & 168,530 & 48 & 39 & 46 \\
Minimum & 31 & 40 & 89 & 87 \\
$\begin{array}{c}\text { Maksimu } \\
\text { m }\end{array}$ & 83 & 90 & 59,5 & 59,5 \\
Median & 63 & 74 & & \\
\hline
\end{tabular}

Perbandingan nilai rata-rata hasil belajar ranah kognitif tiap kelompok tersaji dalam Gambar 1.

RATA-RATA NILAI HASIL BELAJAR RANAH KOGNITIF

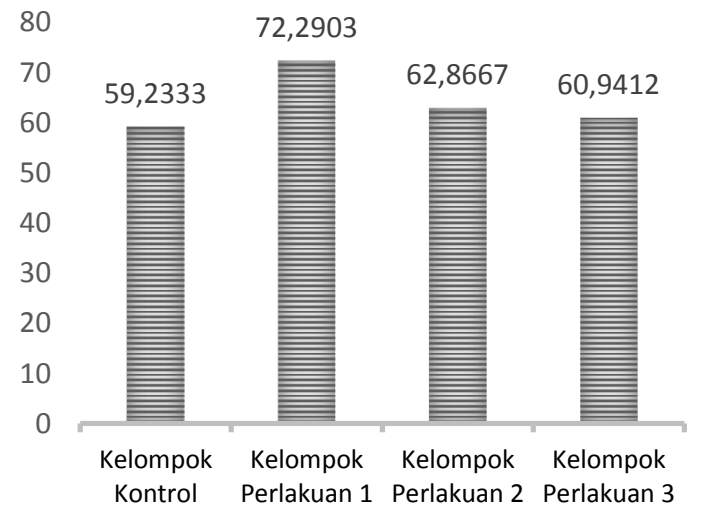

Gambar 1. Perbandingan Rata-rata Nilai Kognitif antarkelompok Perlakuan.
Gambar 1 menunjukan jika kelas perlakuan 1 yang menerapkan model pembelajaran learning cycle $5 \mathrm{E}$ disertai mind map memiliki nilai rata-rata tertinggi jika dibandingkan dengan kelompok perlakuan lainnya. Uji anava satu jalan dipergunakan untuk mengetahui adanya perbedaan yang signifikan di antara kelompok perlakuan. Hasil uji anava terangkum dalam Tabel 3.

Tabel 3. Hasil Uji Hipotesis

\begin{tabular}{ccccccc}
\hline $\begin{array}{c}\text { Uji } \\
\text { Anav } \\
\text { a }\end{array}$ & $\begin{array}{c}\mathbf{F}_{\text {hitu }} \\
\text { ng }\end{array}$ & df & Sig. & $\begin{array}{c}\mathbf{F}_{(\boldsymbol{\alpha}, \text { df })} \\
\mathbf{( 0 . 0 5 , 1} \\
\mathbf{2 4})\end{array}$ & $\begin{array}{c}\text { Keterang } \\
\text { an }\end{array}$ & $\begin{array}{c}\text { Keputus } \\
\text { an Uji }\end{array}$ \\
\hline Hasil & & & & & $\mathrm{F}_{\text {hitung }}>$ & \\
$\begin{array}{c}\text { Belaja } \\
\text { r }\end{array}$ & 7.43 & 12 & 0.00 & 2.440 & $\begin{array}{c}\mathrm{F}_{(\alpha, d f)} \\
\text { Sig. }\end{array}$ & $\mathrm{H}_{0}$ \\
$\begin{array}{c}\text { Kogni } \\
\text { tif }\end{array}$ & 6 & 4 & 0 & & $\begin{array}{c}\text { Ditolak } \\
0.050\end{array}$ & \\
\hline
\end{tabular}

Tabel 4. Selisih Rata-rata Nilai Kogintif dan Signifikansi Uji LSD antarkelompok Perlakuan.

\begin{tabular}{ccccc}
\hline \multirow{2}{*}{ Perlakuan } & \multicolumn{4}{c}{ Perlakuan } \\
\cline { 2 - 5 } & Kontrol & $\begin{array}{c}\text { Perlakuan } \\
\mathbf{1}\end{array}$ & $\begin{array}{c}\text { Perlakuan } \\
\mathbf{2}\end{array}$ & $\begin{array}{c}\text { Perlakuan } \\
\mathbf{3}\end{array}$ \\
\hline Kontrol & - & 13,057 & 3,633 & 1,708 \\
Perlakuan & 13,057 & Sig. 0.000 & Sig. 0.240 & Sig. 0.568 \\
$\mathbf{1}$ & Sig. & - & 9,424 & 11,349 \\
& 0.000 & & Sig. 0.002 & Sig. 0.000 \\
Perlakuan & 3,633 & 9,424 & & 1,925 \\
$\mathbf{2}$ & Sig. & Sig. 0.002 & - & Sig. 0.520 \\
Perlakuan & 0.240 & & & \\
$\mathbf{3}$ & 1,708 & 11,349 & 1,925 & - \\
\hline & Sig. & Sig. 0.000 & Sig. 0.520 & \\
\hline
\end{tabular}

Tabel 3 menunjukan jika hasil uji anava menyatakan bahwa $\mathrm{H}_{0}$ penelitian ditolak. Hal ini menandakan bahwa terdapat perbedaan hasil belajar di antara kelompok perlakuan. Uji anava hanya bisa menunjukan adanya perbedaan yang signifikan diantara kelompok perlakuan, namun belum bisa menentukan perlakuan mana yang membuat perbedaan. Uji LSD sebagai uji lanjut dari uji anava dipergunakan untuk mengetahui perlakuan mana yang membuat perbedaan signifikan. Hasil uji LSD terangkum dalam Tabel 4.

Tabel 4 menunjukan bahwa kelompok perlakuan 1 meliki perbedaan terbesar jika dibandingkan dengan kelompok kontrol, sedangkan kelompok perlakuan 2 dan perlakuan 3 tidak memiliki perbedaan hasil yang dignifikan dengan kelompok Kontrol. Hasil uji statistic membuktikan bahwa penerapan model pembelajaran learning cycle $5 \mathrm{E}$ disertai teknik mencatat mind map berpengaruh terhadap hasil belajar ranah kognitif siswa pada kelompok perlakuan 1 (VIII A).

Respon siswa kelompok perlakuan 1 selama mengikuti pembelajaran sangat baik yang terlihat dari 
keaktifan siswa dalam mengikuti praktikum dan membuat mind map secara kreatif. Siswa termotivasi dalam mengikuti praktikum, terbukti dengan kemauan siswa untuk melakukan pengamatan percobaan ingenhoz di jam istirahat. Siswa bersedia untuk mengerjakan tugas kelompok yaitu membuat mind map pada kertas karton.

Penerapan model pembelajaran learning cycle 5E di kelas perlakuan 2 (VIII B) kurang berpengaruh terhadap hasil belajar siswa. Respon siswa dalam mengikuti pembelajaran masih kurang memenuhi harapan. Motivasi siswa dalam mengikuti pelajaran masih kurang yang terlihat dari tidak ada satupun siswa yang melakukan pengamatan akhir saat praktikum ingenhoz yang seharusnya bisa dilakukan di jam isirahat. Supina (2013) menyebutkan bahwa motivasi belajar siswa merupakan faktor pendorong suksesnya pembelajaran, sebab tanpa adanya motivasi belajar yang tinggi proses belajar akan terhambat yang akan berimbas pula pada hasil belajar siswa. Patimah (2014) juga berpendapat jika terdapat hubungan antara motivasi belajar dengan hasil belajar siswa. Setyowati (2007) mengungkapkan bahwa adanya motivasi akan mendorong siswa agar belajar untuk mencapai sasaran dan tujuan yang diinginkan, serta motivasi juga dapat menggerakan perilaku siswa kearah yang positif sehingga mampu menghadapi segala tuntutan dan kesulitan sehingga mampu menanggung resiko yang dihadapinya.

Penerapan model belajar DI yang disertai teknik mind map di kelas perlakuan 3 (VIII G) juga kuirang berpengaruh terhadap hasil belajar siswa. Pembuatan mind map oleh siswa berjalan kurang maksimal, hal ini dikarenakan siswa kurang mengembangkan kata-kata kunci yang sudah dibahas bersama guru. Banyak siswa yang belum menggunakan imajinasinya sendiri dalam membuat mind map. Kreativitas dan imajinasi yang dikembangkan sendiri oleh pembuat mind map merupakan kunci keberhasilan dari teknik mind map. Merchie \& Van Keer (2013) menambahkan bahwa mind map yang baik harus mudah dibaca, memiliki struktur radial, menggunakan informasi tekstual yang cukup, serta adanya pengembangan dari kata kunci yang terdapat di sebuah cabang.

Penerapan model pembelajaran DI di kelas kontrol (VIII H) masih kurang maksimal. Penggunakan metode presentasi dan diskusi panel dalam pembelajaran tidak berjalan maksimal. Interaksi siswa pada sesi tanya jawab tidak berjalan dengan baik. Siswa masih belum terbiasa melakukan presentasi yang terlihat kepercayaan diri siswa yang kurang ketika maju ke depan, pengunakan intonasi suara yang pelan, serta siswa masih bingung dalam membawakan materi presentasi. Saat diskusi panel banyak siswa yang aktif sendiri dan kurang memperhatikan temannya yang sedang presentasi. Chong \& Yeo (2016) menyebutkan jika perhatian adalah kunci keberhasilan dalam pembelajaran dan langkah awal dalam mempelajari sesuatu yang baru, agar berhasil dalam pembelajaran siswa harus berkonsentrasi pada pelajaran serta menghindari kegiatan yang tidak relevan seperti mengobrol dengan teman dan melamun.

\section{KESIMPULAN}

Hasil penelitian menunjukan bahwa penggunakan model pembelajaran learning cycle 5E disertai mind map berpengaruh signifikan terhadap hasil belajar siswa kelas VIII SMP Negeri 5 Karanganyar.

\section{DAFTAR PUSTAKA}

Anderson, L. W., \& Krathwohl, D. R. (2010). Kerangka Landasan Untuk Pembelajaran, Pengajaran, dan asesmen. Yogyakarta: Pustaka Pelajar.

Aunurrahman. (2012). Belajar dan Pembelajaran. Bandung: Alfabeta.

Buzan, T. (2013). Buku Pintar Mind Map. Jakarta: Gramedia Pustaka Utama.

Bybee, R. W. (2009). The BSCS 5 E Instructional Model and 21 'st Century Skills. Colorado Spring, CO: BSCS. Diambil kembali dari http://sites.nationalacademies.org/cs/groups/dbassesi te/documents/webpage/dbasse_073327.pdf

Bybee, R. W., Taylor, J. A., Gardner, A., Van Scotter, P., Powell, J. C., Westbrook, a., \& Landes, N. (2006). The BSCS 5E: Origins and Effectiveness. . Colorado Spring, CO: BSCS.

Chong, C.-H., \& Yeo, K.-J. (2016). Why Students Fail In History: A Minor Case Study In Malaysia And Solution From Cognitive Psycology Perspective. Mediterranean Journal of Sciences, 7(1), 518-526.

Dahar, R. W. (2011). Teori-Teori Belajar dan Pembelajaran. Jakarta: Erlangga.

Merchie, E., \& Van Keer, H. (2013). Schematizing and Processing Informationnal Texts With Mind Maps In Fifth and Sixth Drade. Middle Grades Reseach Journal, 8(3), 61-68.

Patimah, S. (2014). Hubungan Mitivasi Belajar dengan Hasil Belajar Siswa pada Mata Pelajaran Ilmu Pengetahuan Sosial Kelas IV SD Negeri 18/I Desa Teluk. Artikel Penelitian Tidak Dipublikasikan. Universitas Jambi, Jambi. Dipetik Juny 1, 2016, dari http://e-

campus.fkip.unja.ac.id/eskripsi/data/pdf/jurnal_mhs/ artikel/A1D109200.pdf

Purwanto. (2013). Evaluasi Hasil Belajar. Yogyakarta: Pustaka Pelajar.

Rustaman, N., Ahmat, Y., Yudianto, S., Rhochintainawati, D., Nurjhani, M., \& Subekti, R. (2008). Strategi 
Belajar Mengajar Biologi. Bandung: Jueusan Pendidikan Biologi FMIPA UPI.

Setyowati. (2117). Pengaruh Motivasi Belajar Terhadap Hasil Belajar Siswa Kelas VII SMPN 13 Semarang. Skripsi Tidak Dipublikasikan. Universitas negeri semarang, Semarang.

Shoimin, A. (2014). 68 Model Pembelajaran Inovatif dalam kurikulum 2013. Yogyakarta: Ar-Ruzz Media.

Somantri, A., \& Muhidin, S. A. (2006). Aplikasi Statistika dalam Penelitian. Bandung: Pustaka Setia.

Sudjana, N. (2011). Penilaian Hasil Proses Belajar Mengajar. Bandung: Rosdakarya.

Supina. (2013). Pengaruh Motivasi terhadap Hasil Belajar Siswa Kelas X.C pada Mata Pelajaran Ekonomi di SMA. Artikel Penelitian Tidak Dipublikasikan. Universitas Tanjungpura, Pontianak. Dipetik Juny 1, 2016, dari http://download.portalgaruda.org/article

Wena, M. (2009). Strategi Pembelajaran Inovatif Kontenporer, Suatu Tinjauan Konseptual Operasional. Yogyakarta: Inti Media. 